\title{
Desafios gerenciais para a reconfiguração da administração burocrática brasileira
}

RÁMODACNHARFANE*

\section{Resumo}

0 trabalho focaliza o problema dos limites da construção das novas burocracias gerenciais, no contexto das reformas administrativas contemporâneas. 0 argumento central é o de que de as reformas gerenciais encontram considerável dificuldade para estabelecer os novos modelos institucionais orientados pela performance devido à preponderância do ajuste fiscal. A construção do argumento é baseada em dois níveis complementares de análise. 0 primeiro abrange evidências comparativas produzidas por estudos e pesquisas que analisaram os limites da implementação de reformas gerenciais da administração pública em diversos países e diversas condições. 0 segundo focaliza nas razões específicas da não implementação das novas burocracias orientadas pela performance no contexto da estratégia de reforma administrativa gerencial perseguida pelo Governo Federal brasileiro em 1995.

Palavras-chave: Reforma do Estado. M udança institucional. Burocracia. Nova gestão pública. Políticas públicas. Governança pública.

* PhD em Políticas Públicas e Planejamento pela Cornell U niversity, EUA. Professor /Pesquisador do Mestrado e Doutorado em Ciência Política na Universidade Federal de Pernambuco. Bolsista de Produtividade de Pesquisa do CNPQ . 


\section{Introdução}

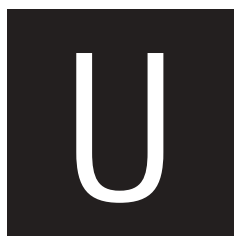

$\mathrm{m}$ dos desafios centrais para as sociedades contemporâneas é o de como produzir sistemas hierárquicos de autoridade compatíveis com a expansão das liberdades, competição política e da demanda crescente por delegação de poderes. Fatores estruturais tais como a globalização, a democratização e a crise fiscal tornam decisivo o problema dos limites da intervenção tradicional do Estado. Neste contexto, o problema da tensão entre burocracia e democracia aparece como tema de crucial centralidade para a configuração de novos modelos de governança na produção de políticas públicas.

As reformas gerenciais que ocorrem em diversos contextos a partir dos anos 90 colocam como problema central a necessidade de redefinir os modelos de gestão pública a partir de novos modelos institucionais que permitam ampliar a capacidade de governar, a legitimidade política e a eficiência na provisão de bense serviços para a sociedade. É neste contexto que emerge um novo conjunto de crenças sobre novas formas de reorganização burocrática, centradas em novos padrões de relacionamento entre o Estado, 0 mercado e a sociedade civil e orientados pela produtividade gerencial.

$\mathrm{N}$ as suas diferentes versões, as reformas gerenciais apresentam como questão básica a necessidade de produção e consolidação de novas matrizes institucionais orientadas por princípios de descentralização, accountability, inclusão social, e eficiência fiscal, fazendo emergir um conjunto de uma nova reflexão sobre os limites das formas tradicionais e burocráticas de gestão pública ${ }^{1}$. A tensão entre burocracia e democracia passa a ser decisiva para a construção das novas burocracias gerenciais. Raras

1 No sentido mais amplo, esta reflexão remete aos limites da intervenção do Estado na sociedade e economia contemporâneas. Nos anos 90 inicia-se uma profunda reflexão sobre o esgotamento das formas tradicionais de intervenção do Estado, e, ao mesmo tempo uma compreensão mais profunda sobre a inviabilidade de uma sociedade organizada apenas pelos M ercados. 
foram as experiências de reformas que não se fizeram acompanhar por um questionamento da burocracia tradicional e pela proposição de criar um novo modelo centrado em modelos institucionais participativos em que a descentralização, a expansão dos controles e da delegação. No Brasil, conforme analisaremos a seguir, a experiência de reforma administrativa no Governo Federal, em 1995, foi profundamente marcada por uma tentativa de consolidar um novo desenho institucional para a administração pública, com modelos flexíveis de gestão e regulação.

A busca por modelos flexíveis de governança pública emerge como resposta aos processos de ampliação da democracia política² nas sociedades contemporâneas. As crescentes demandas por democratização e participação social na gestão pública, passam exigir dos sistemas tradicionais de autoridade uma maior complexidade decisória, maior abertura aos conflitos ge-

Dahl (1993) lança as fundações para o argumento de que "mercados livres não bastam", evidenciando os papéis do Estado. A questão normativa sobre o papel do Estado passa a ser decisiva para as políticas de reforma administrativa. Em versões mais modernas, admite-se que o Estado deve fornecer as bases para o funcionamento das sociedades de mercado tais como regras, normas, padrões de regulação e um conjunto de políticas públicas que são de exclusiva competência do Estado. Mesmo entre as versões que consideram que "o Estado é um problema", existem basicamente duas tradições: a versão que considera ser papel do Estado a provisão de bens públicos clássicos e a versão que considera que o Estado deve intervir na provisão de políticas sociais em condições de pobreza e vulnerabilidade social. O utra questão orientadora das reformas passou a ser a discussão em torno do "tamanho do Estado", que passou a ser um dos problemas para a manutenção dos equilíbrios fiscais nas sociedades contemporâneas. Reduzir os gastos e o quantitativo com pessoal passou a ser um discurso típico da nova agenda de reformas.

2 Dahl (1972) considera que as democracias possuem duas dimensões básicas: a inclusividade e a competição política. As poliarquias são modelos ideais que maximizam tais aspectos. Democracias seriam consideravelmente variáveis no mundo real e apresentariam diversidade institucional no tocante à sua capacidade de promover "accountability", participação, representação, e, especialmente, orientação para aspectos redistributivos que têm mais a ver com a promoção da equidade e justiça social. Na teoria democrática contemporânea existe um amplo debate sobre os requisitos e condições para a efetividade democrática. 0 debate entre os minimalistas que afirmam ser a democracia um método, um arranjo institucional para promover a competição política, e, por outro lado, os substantivistas que consideram aspectos relativos à capacidade das democracias em promover redistribuição e promoção do bem-estar social, é um dos temas marcantes. Shapiro (2005) fornece uma excelente compreensão dos termos do debate sobre a teoria democrática contemporânea. 
rados pela inclusividade e da competição política e, mais atentos a questões relativas à eficiência. Descentralização, controles sociais, flexibilidade, e inclusão social passam a ser valores ensejados pelas sociedades democráticas e conflitantes com modelos burocráticos tradicionais que não colocam o desempenho e a produtividade gerencial como tema central.

Este artigo discute o problema dos limites da construção das novas instituições no contexto das reformas administrativas gerenciais dos anos 90 . 0 principal argumento é o de que as reformas gerenciais encontram considerável dificuldade para estabelecer os novos modelos institucionais em diversos contextos e sob variadas condições. 0 propósito central do trabalho é o de discutir as razões pelas quais as tentativas de compatibilizar a tensão entre burocracia e democracia usualmente enfrentam consideráveis limites.

A construção do argumento é baseada em dois níveis complementares de observação e análise. 0 primeiro abrange evidências comparativas produzidas por estudos e pesquisas que analisaram os limites da implementação de reformas gerenciais da administração pública em diversos países e diversas condições, chamando a atenção para o problema da implementação das novas formas organizacionais. 0 segundo focaliza nas razões específicas no projeto de reforma administrativa perseguida pelo Governo Federal brasileiro em 1995.

0 artigo está organizado da seguinte forma: na próxima seção, o artigo discute as reformas gerenciais e seus modelos institucionais para a reorganização da burocracia pública. São apresentados os pressupostos do paradigma gerencial e as novas formas organizacionais sugeridas pela experiência internacional de reformas administrativas a partir dos anos 90 . Em seguida, são apresentadas evidências comparativas sobre os limites de implementação das reformas gerenciais em diversos contextos. São apresentadas também diversas razões para a interpretação teórica deste importante fenômeno. Em seguida, a análise recai sobre a análise da experiência da reforma gerencial brasileira, mostrando que a condição de preponderância do ajuste fiscal foi decisiva para a não-adesão à construção 
de modelos organizacionais orientados pela performance no Brasil. Por fim, são apresentadas as considerações finais da análise.

\section{Performance, controle e accountability nas reformas gerenciais}

A emergência do gerencialismo, nos anos 90, como paradigma orientador das reformas da administração pública ${ }^{3}$ decorre da clara preocupação teórica dos modelos e teorias tradicionais em oferecer respostas à relação entre as formas de organização institucional e performance ${ }^{4}$ administrativa. Partindo da premissa de que as instituições (e o desenho institucional) importam para a produção de incentivos para a criação de novas burocracias, os gerencialistas orientam suas problematizações a partir da seguinte questão: "que desenhos institucionais permitem reconfigurar a eficiência dos modelos de gestão?"5.

3 Bowornwathana (1997) argumenta que o estudo comparativo das políticas de reforma administrativa tem sido orientado por um novo paradigma que ele denomina de "nova governança democrática" "(new democratic governance)". Este paradigma tem princípios que emergem para dar resposta a quatro questões essenciais: sobre o papel e funções do governo, sobre os mecanismos de funcionamento do governo, a organização dos controles e da 'accountability', e, por fim, questões relativas à performance das políticas públicas.

40 termo performance, neste artigo, é utilizado em sentido mais amplo do que os resultados efetivamente atingidos pelas organizações, ou pelo Governo. Ela deve ser entendida como relacionada à existência (ou não) de mecanismos que possibilitem a elevação da capacidade institucional de organizar, gerenciar e coordenar políticas públicas em diferentes níveis. A performance passa, neste sentido, por um complexo conjunto de dimensões tais, como sistemas de mérito e profissionalização, grau de fragmentação e delegação, consistência estrutural, capacidade funcional, e capacidade de integração. Como mostra Cameron (1986), a questão da performance organizacional é marcada por considerável dissenso entre os diversos autores, tornando o problema de como mensurar a efetividade, questão delicada para os analistas do comportamento burocrático, especialmente na Administração Pública.

5 Vários autores na tradição do novo institucionalismo, tais como N orth (1990), O strom (1990), Putnam (1993), Hall and Taylor (1996), Przeworski (1998), Rodrik (2003) argumentam basicamente que a qualidade do desempenho da intervenção pública depende fundamentalmente dos mecanismos institucionais que articulam as relações entre a sociedade, o Estado e o mercado. As instituições permitem que sejam reconfiguradas em novas bases as questões relativas à 
A teoria orienta que o principal problema da administração pública é, na realidade, um problema de construção de incentivos que possam superar a crônica ineficiência dos modelos tradicionais ${ }^{6}$. M odelos marcados por instituições dotadas de maior accountability, credibilidade, e por sistemas de incentivos que potencializem a capacidade ${ }^{7}$ gerencial das administrações públicas $^{8}$ seriam decisivos para os novos sistemas de governança ${ }^{9}$.

confiança, credibilidade e às formas de superação do conhecido problema de ação coletiva na provisão das políticas públicas. De forma mais ampla, a qualidade institucional permite reduzir os custos de transação nas relações entre Estado e sociedade.

60 importante estudo desenvolvido pelo Banco Mundial ("World Bank", 1997) expressa claramente como as recomendações institucionalistas estão convertidas para a orientação das políticas de reforma do Estado, especialmente nas sociedades em desenvolvimento. No capítulo 5 - "Building Institutions for a Capable Public Sector" - está clara a premissa institucionalista de que a construção de matrizes institucionais para ampliar a capacidade de estado é decisiva para ampliar a efetividade das políticas públicas. A ênfase institucionalista difere das estratégias de políticas anteriores, pela focalização nas estruturas de incentivos que organizam e estruturam as ações das agências governamentais. A capacidade de Estado depende fundamentalmente das regras e normas que consolidam, em cada contexto, as lógicas e realidades dos modelos específicos de governança. A principal recomendação do Banco M undial é a de que os Governos devem partir de três eixos modernizantes: a) ampliação da capacidade de coordenação dos governos centrais sobre as políticas públicas; b) a eficiência dos sistemas de delegação a partir da combinação de flexibilidade e "accountability"; e c) as políticas de incentivos para a motivação e a profissionalização dos servidores públicos.

70 termo capacidade gerencial é utilizado aqui como próximo de state capacity. Grindlee (1996) considera que state capacity é um conceito multidimensional usado na literatura das políticas públicas e que está diretamente associado a capacidades institucionais, técnicas, administrativas, e políticas de um dado sistema gerencial em implementar efetivamente suas políticas públicas.

8 Peters and Lawrence (1998) argumentam que as concepções tradicionais de organização e funcionamento das burocracias públicas passam por profunda revisão com as políticas de reformas gerenciais. Em primeiro lugar, as reformas sugerem que os novos modelos de governança sejam orientadas por modelos participativos na gestão de políticas públicas onde o Estado passa a ser mais um dos atores estratégicos. As reformas permitem a emergência e a construção de novos modelos de governança tais como: "governance without government"; "hollow states and governments"; e "negotiated states and economies". A idéia básica comum a estes modelos é a de expansão dos papéis e responsabilidades dos diversos atores sociais nas políticas públicas, em contraposição aos modelos tradicionais de gestão centrados no governo como protagonista nos processos de formulação e implementação das políticas públicas.

90 conceito de governança está sendo utilizado neste artigo em sintonia com Rhodes (1997) que a define "como significando mudança: a) nas estruturas e políticas públicas; b) nos processos de gestão pública; c) nas condições básicas que estruturam a ordem regulatória de uma dada sociedade; e, e) no sentido mais amplo, aos novos métodos de gestão de uma dada sociedade". 
Neste sentido, passa a ser crucial a questão de como elevar e empreender reformas na administração pública em diferentes contextos ${ }^{10}$ e condições ${ }^{11}$. No contexto das reformas dos anos noventa, estas passam a ser uma questão de primeira ordem, num contexto de forte escassez fiscal, expansão da democracia e, especialmente, por uma crítica aos excessivos níveis de intervenção pública ${ }^{12}$. As políticas de modernização gerencial começam a fazer parte de uma agenda mais ampla de políticas que estão diretamente associa-

A definição de governança sugerida envolve interação estratégica interdependente entre atores sociais situados entre o mercado e o Estado na gestão e implementação de políticas públicas. As reformas gerenciais envolvem diversos modelos de governança. Bresser (2007) considera que as experiências de reformas administrativas representam, em seu sentido mais amplo, uma transformação estrutural nos modelos tradicionais de governança.

10 Analisando a relação entre desenvolvimento e mudança institucional, Evans (2002) desenvolve 0 argumento do "institutional monocropping" chamando a atenção para a importância de que as políticas de reforma sejam ajustadas às condições e contextos em que elas se inserem, evitando a adesão a políticas do tipo "blueprint" em que as características institucionais, especialmente as de natureza política tais como participação e deliberação pública sejam consideradas nos novos modelos de governança. Para as reformas administrativas, grande parte da literatura que trabalha com as "falhas de implementação" (REZENDE, 2004) consideram que os modelos do tipo "one-size-fits all" são usualmente fadados a falha seqüencial.

110 problema de como passar de sistemas tradicionais para sistemas modernos de gestão quando considerado em nível mais amplo de análise, está diretamente conectado ao problema da mudança ou transformação social. Analisando o caso da modernização social e econômica ocorrida na China contemporânea, Nee and Opper (2007) consideram que a mudança de sistemas de gestão tradicional para sistemas modernos de gestão está diretamente ligada às políticas de reformas administrativas e aos novos desenhos institucionais. Eles apontam para 0 importante papel dessas transformações, mostrando que a reorganização das relações entre a burocracia pública e os partidos políticos e a descentralização fiscal, foram dois mecanismos decisivos para a consolidação de uma nova ordem institucional na governança chinesa.

12 Heredia e Schneider (2003) argumentam que as reformas administrativas contemporâneas podem ser comparativamente compreendidas a partir de três modelos básicos: a) as reformas dos sistemas de gestão de pessoal ("civil service reform"); b) as reformas dos sistemas de gestão pública; e c) as reformas dos mecanismos de "accountability". No primeiro modelo, as questões centrais estão relacionadas à questão da promoção do mérito e da profissionalização no serviço público. Nas reformas na gestão pública, as questões fundamentais estão ligadas à promoção da eficiência e da responsividade da burocracia. Por fim, nos modelos de reformas pela "accountability", a idéia central está relacionada aos propósitos de fortalecer os mecanismos de controle da sociedade civil e política sobre as burocracias públicas. 
das à necessidade de controlar os desequilíbrios fiscais e os de construir instituições públicas capazes de promover valor público (M O O RE, 1997)13.

As reformas gerenciais partem do pressuposto de fazer a burocracia pública "funcionar melhor, a um menor custo". U ma nova Administração Pública construída a partir de flexibilidade gerencial, descentralização, autonomia, e novas formas de gerenciamento são indispensáveis à elevação da performance ${ }^{14}$. Esta não depende não apenas de controle fiscal e redução do tamanho e grau de intervenção do Estado, mas, sim de "novos modelos institucionais" capazes de permitir que as organizações públicas passem orientadas por parâmetros de eficiência e efetividade. A questão de como criar os novos incentivos decisivos para a organização pela performance torna-se problema central no design de reformas administrativas, a partir dos anos 90.

Considerável parcela deste problema reside na necessidade de institucionalizar uma nova matriz organizacional na qual se reorganizam as articulações entre as agências que formulam e as que executam as diversas políticas públicas. 0 ponto central da questão reside, portanto, na relação

13 Embora o conceito de "valor público" seja abstrato e dotado de considerável ambigüidade, Moore (1997) estabelece algumas condições básicas para que a Administração Pública seja orientada pelo valor público: a) uso intensivo de estratégias de avaliação e análise de políticas públicas; b) institucionalização de avaliação de custo-efetividade; c) focalização crescente nas demandas e nas políticas de qualidade no atendimento aos consumidores; d) ampliação das capacidades da gestão política das políticas públicas; e e) ampliação e fortalecimento das instituições de "accountability".

14 Os gerencialistas trabalham com a premissa do esgotamento dos modelos burocráticos e lançam as condições institucionais básicas para os modelos organizacionais pós-burocráticos flexíveis. Segundo Barzelay (1992), uma organização gerencial "ideal" deve ser voltada para: a) orientação das políticas organizacionais pelas necessidades básicas dos clientes-consumidores; b) ampliação da coerência organizacional; c) ampliação das capacidades de definição da missão e dos resultados organizacionais; d) controle dos custos organizacionais; e) capacidade de adaptação organizacional aos ambientes e contextos de implementação das políticas públicas; f) capacidade de competição e trabalho compartilhado com outras agências do Governo na provisão de serviços; g) capacidade de construção das estratégias organizacionais em decorrência da interação com os seus clientes; h) ampliação do poder e autoridade dos gerentes que implementam políticas públicas visando ampliar a qualidade das políticas. 
entre delegação e desempenho. A burocracia tradicional deve ceder espaço para modelos de governança pública orientada pelo desempenho, onde se intensificam os processos de delegação para as agências implementadoras de políticas públicas. A "accountability" tradicional pautada por regras passa a ser reconfigurada em termos de uma "accountability" de resultados.

\section{Limites para a implementação das burocracias gerenciais}

A criação de uma nova matriz institucional orientada pela performance é um dos principais limites para a reforma da Administração Pública. Polidano, Hulme and M inogue (1997) consideram que a institucionalização das reformas gerenciais é problemática em diversas condições e contextos. Eles argumentam que a relação entre as intenções e os resultados obtidos pelas reformas administrativas são consideravelmente complexos, ambíguos e, que, de modo geral, a experiência comparada, especialmente nos países em desenvolvimento, revela consideráveis limites, mesmo quando existem compromissos formais dos governos para realizar tais reformas no modelo de governança.

O êxito relativo das reformas gerenciais na Inglaterra, Austrália e na Nova Zelândia dependeu, em grande parte, de um conjunto de condições específicas - especialmente forte apoio político para as reformas nos anos 80 e 90 - em que tais mudanças foram promovidas. Essas mudanças são mais difíceis de ocorrer em contextos de países em desenvolvimento nos quais se verificam sistemas de gestão de políticas públicas marcadas por elevados níveis de fragmentação e descoordenação, elevada interferência da política sobre a administração e com reduzida performance e capacidade gerencial. Criar instituições orientadas pela performance aparece como um dos principais problemas de implementação dos novos modelos de governança.

Jann e Reichard (2002) argumentam que as reformas enfrentam considerável resistência, organizada para implementar modelos organizacionais 
orientados por resultados. Pollitt e Bouckaert (2000) consideram que os resultados de implementação das reformas variam sensivelmente entre grupos específicos de países ${ }^{15}$. Polidano (2001) considera que as reformas administrativas tendem a falhar sequencialmente na implementação. Sua análise comparada sugere que as estratégias e táticas de implementação das reformas são variáveis e realmente importam para explicar o êxito ou fracasso das reformas administrativas. Para ele, diferentes modelos de reformas descentralização, nova gestão pública, state capacity - são igualmente propensos a falha seqüencial. Na sua análise, ele chama a atenção para três importantes dimensões analíticas que assumem relevância para explicar a variabilidade nos casos de reformas administrativas: o escopo das reformas, o papel das agências financiadoras e as transformações ensejadas no padrão de liderança. Rezende (2004) considera que as reformas são processos que desencadeiam cadeias de "falhas seqüenciais" que se originam na tensão entre o controle fiscal e a delegação de autonomia gerencial. Em condições de elevada demanda por ajuste fiscal como tem sido a experiência de reformas para um considerável conjunto de países, o dilema de compatibilização entre equilíbrio fiscal e delegação se torna mais agudo.

A experiência comparada revela que, em um conjunto considerável de casos, especialmente na América Latina ${ }^{16}$, a preponderância do ajuste

15 Nos países considerados "líderes" do movimento gerencialista - Inglaterra, Austrália, Nova Zelândia, e EUA - se verificam as maiores taxas comparadas de êxito. Na experiência da França, nos países nórdicos, nos Países Baixos e no Canadá foram modernizadores mais lentos e cautelosos, com menor recorrência às estratégias agressivas de privatização, menor uso de processos de 'downsizing' e bem menos em relação às idéias gerenciais, pelos processos de criação das novas instituições flexíveis, bem como da introdução de mecanismos de mercado no interior das organizações do setor público. Por outro lado, os países em desenvolvimento e em transição para os mercados implementaram com graus diferenciados de sucesso as reformas gerenciais.

160 estudo IDB (1997) revela que, no contexto latino-americano, os processos de descentralização que se expandiram com a democratização foram limitados por um amplo conjunto de iniciativas voltadas para promover o ajuste fiscal. No Brasil, a modernização fiscal adquiriu centralidade, a partir de meados dos anos 90 , e promoveu uma reconfiguração do 
fiscal sobre a mudança institucional representa um dosfatores críticos para implementar modelos orientados pela performance. Especialmente em condições de elevada demanda por ajuste fiscal, os políticos e burocratas percebem que os ganhos ou efeitos políticos das decisões sobre o ajuste fiscal são mais "rápidos" e com "maior visibilidade política" do que transformar os incentivos institucionais dos modelos de governança. Mudança institucional depende de ação coletiva e tempo e, portanto não se mostram politicamente atrativas. N este sentido, embora fundamentais para a elevação do desempenho, estratégias voltadas para a construção das novas instituições e dos incentivos internos à burocracia são quase sempre colocadas como "segunda prioridade" em relação ao ajuste fiscal.

A descentralização da gestão - especialmente de orçamentos e de gestão de pessoal - visando a autonomia decisória, responsabilização burocrática e accountability de resultados não se sintonizou com os propósitos de equilíbrio fiscal. A descentralização da gestão - especialmente de orçamentos e de gestão de pessoal - visando a autonomia decisória, responsabilização burocrática, e controles por resultados, é percebida pelas elites burocráticas e políticas como um processo de produção de ineficiências na gestão pública. A nova burocracia e suas instituições se tornam consideravelmente arriscadas, especialmente em contextos marcados por forte tradição de rent-seeking, corrupção, e clientelismo. Raros são os casos em que as mudanças propostas foram implementadas, e os desafios políticos, institucionais, e técnicos para conseguir a cooperação com os objetivos da reforma gerencial são ainda intensos.

Por outro lado, a expansão da delegação tende a exacerbar os problemas de coordenação e de incoerência estrutural entre a formulação e

federalismo brasileiro. As políticas de modernização fiscal foram voltadas para promover eficiência via "hard budget constraints", redesenho da estrutura tributária, reconfiguração da autonomia sobre a transferência de recursos, bem como limitações sobre a capacidade de empréstimo e endividamento dos Estados. A Lei de Responsabilidade Fiscal (LRF) é um claro exemplo da modernização fiscal brasileira. 
implementação de políticas públicas, especialmente em contextos de fortes ambigüidades estruturais ${ }^{17}$. De forma paradoxal, descentralização e delegação terminam por produzir mais controles burocráticos. Na experiência comparada, as reformas gerenciais muito raramente foram acompanhadas por redução da burocracia. No caso dos países em desenvolvimento, com uma frágil tradição do controle, este é um problema que aparece como decisivo. Em contextos de relações muito permeáveis entre a política e a administração, como o caso brasileiro, a descentralização é quase sempre associada a efeitos não-intencionais como corrupção, clientelismo e uso indevido dos recursos públicos, bem como ineficiência fiscal.

A cooperação dos atores estratégicos para a implementação das novas instituições burocráticas depende fundamentalmente da cooperação simultânea dos atores estratégicos na arena de reformas para os propósitos de ajuste fiscal e mudança institucional. O bserva-se, na análise comparativa das reformas gerenciais, que o padrão emergente se aproxima do que poderíamos dizer o padrão dual de cooperação, no qual as experiências de ajuste fiscal são privilegiadas, inibindo as chances de modelos de transformação na estrutura de delegação e controle entre formulação e implementação de políticas públicas.

A resposta é oferecida a partir da forma em que os atores com poder de veto sobre as reformas fazem escolhas estratégicas a partir de como compreendem o que chamamos de dilema do controle, sob o qual reside, na nossa argumentação, o ponto nodal para a construção da nova matriz institucional orientada pela performance.

17 No campo disciplinar das políticas públicas, os chamados paradigmas da ambigüidade marcados pelos trabalhos de James March e Johan O Isen ocupam posição privilegiada. March atribui grande parte dos problemas de implementação à questão da ambiguidade. Muitos dos problemas de inconsistência entre formulação e implementação seriam evitados se os níveis de ambigüidades fossem reduzidos pelos formuladores, e, ao mesmo tempo, por criar procedimentos que reduzam a ameaça de captura por grupos de interesses. A análise da implementação nesta tradição parte da premissa de que as políticas são carregadas de contradições e ambigüidades no seu processo decisório. 
O dilema do controle pode ser compreendido a partir do impasse que se estrutura, em termos da demanda, por controle em relação ao ajuste fiscal e à matriz gerencial. Iniciativas de promover o ajuste fiscal, usualmente estão associadas a políticas que exigem maior nível de controle e sistematização sobre a burocracia e suas organizações. N este sentido, são típicos das políticas de controle fiscal a modernização das auditorias, dos sistemas de prestação de contas, controle orçamentário, das formas de pagamentos, dos controles sobre salários, sobre promoções, vantagens, gratificações e, especialmente sobre a contratação de servidores públicos. o controle é o mecanismo decisivo para que se possa atingir maior performance fiscal. Este problema emerge como a tensão essencial a ser superada e em que condições é possível para alinhar os padrões de cooperação com uma demanda conflituosa em torno do controle.

$\mathrm{Na}$ análise comparada das reformas gerenciais, o que se verifica e é típico que os atores compreendam tal "incoerência estrutural" como incentivos altamente contraditórios, dificultando a cooperação simultânea e, conseqüentemente, reduzindo suas chances de implementação e sustentabilidade no tempo. As reformas, sobretudo em contextos de baixa performance e conservadorismo fiscal, usualmente conseguem apoio para o ajuste fiscal, dado que a cooperação com a redução dos gastos públicos deixa intacto o conjunto de práticas institucionais que, de fato, produzem os problemas crônicos de performance. N este ponto é que reside o paradoxo da implementação das reformas gerenciais.

\section{A reforma gerencial no Brasil: os limites da construção das novas burocracias flexíveis}

Em 1995, com o Plano Diretor da Reforma do Estado formulado pelo MARE - Ministério da Administração Federal e da Reforma do Estado, o governo brasileiro lançou as bases para a institucionalização da re- 
forma gerencial da administração federal. De forma distinta das duas grandes experiências de modernização administrativas ocorridas nos anos 30 e 60 (BRESSER PEREIRA, 1998), a nova estratégia de reforma teve como pressuposto a conexão entre a elevação da performance e a transformação das formas tradicionais de delegação e controle entre as agências do setor público (BRESSER PEREIRA, 2007).

O diagnóstico realizado à época conferia especial atenção ao fato de que considerável parcela do problema da ineficiência burocrática no Brasil estava relacionada ao problema de organização burocrática. 0 redesenho dos incentivos das relações entre formulação e implementação de políticas públicas foi considerado passo decisivo para superar os crônicos problemas de implementação da Administração Pública brasileira. O novo modelo trazia como inovação institucional a criação das organizações orientadas pela performance (PBO s), para conduzir a implementação de um amplo conjunto de políticas públicas em funções consideradas não-exclusivas de Estado, através das organizações sociais e das agências executivas ${ }^{18}$.

Apesar do forte compromisso em reformar os incentivos da Administração brasileira, a nova estrutura de delegação não foi implementada. A proposta de construção da nova matriz institucional foi, no entanto, percebida por diversos atores estratégicos com poder de veto sobre as reformas como diretamente relacionada ao aumento da ineficiência fiscal devido aos

18 De acordo com Bresser Pereira (1998, p.235), o modelo institucional que provavelmente terá maior repercussão é o das organizações sociais. A proposta da reforma é de transformação dos serviços sociais e científicos em entidades públicas não-estatais, entidades sem fins lucrativos, do terceiro setor. Ao serem qualificadas como organizações sociais, as novas entidades públicas, mas, de direito privado, poderão celebrar um contrato de gestão com o Ministério supervisor e terão direito de participar do Estado. A aposta do governo Fernando Henrique Cardoso nas organizações sociais parte, de um lado, da verificação de que a adoção da propriedade pública não-estatal para a realização de serviços sociais de saúde, educação, cultura e pesquisa científica, e, de outro, da convicção de que este tipo de entidade, além de se constituir em um espaço intermediário entre o Estado e o Mercado, contribuindo para o fortalecimento das instituições democráticas, é mais eficiente e garante maior qualidade para a realização destes serviços do que as organizações estatais ou privadas. 
problemas associados de coordenação gerencial que poderiam advir da delegação e flexibilização institucionais. No contexto brasileiro, marcado pela fraca tradição regulatória e de processos históricos de descentralização "descontrolada" a partir da Reforma Administrativa de 1967, bem como de forte pressão por ajuste fiscal, a estratégia de expansão da autoridade foi tida como indevida. Ampliar o espaço de autonomia gerencial, descentralizando e delegando controle sobre a implementação de políticas e, especialmente, sobre controle de recursos financeiros, técnicos e humanos, foi considerado como negativamente relacionado à eficiência fiscal, bem como 0 conservadorismo fiscal e a miopia dos atores estratégicos em torno da relação entre performance (fiscal e gerencial) e desenho institucional.

A reação à reforma esteve associada a ambiguidade e incerteza sobre a natureza do relacionamento entre os M inistérios (agênciasformuladoras) e as novas burocracias responsáveis pela implementação descentralizada de políticas públicas, sobre a capacidade dos mecanismos de controle orientado pela performance e sobre o que vem a ser performance nos diversos níveis de governança. A performance fiscal conflita, portanto, com a performance gerencial ${ }^{19}$. A preponderância do ajuste fiscal não permitiu grandes avanços institucionais na organização da burocracia pública no Brasil. Este resultado é, em grande medida, consistente com os padrões gerais fornecidos pelas evidências das reformas em outros contextos.

A não cooperação com as novas burocracias não ocorreu no caso brasileiro, por razões claras. Primeiro, a nova matriz institucional não era uma proposta dotada de crédito por parte dos atores estratégicos movidos por

19 A estratégia de conformidade da reforma administrativa de 1995 à contingência fiscal foi bem sucedida no Brasil. O Governo brasileiro conseguiu atenuar o processo de expansão acelerada dos gastos públicos, imprimindo mudanças que "atacaram" de frente as raízes do problema, tais como os aumentos indevidos ao funcionalismo, o desconhecimento das informações sobre a máquina do Executivo Federal, bem como os tênues controles sobre as folhas salariais, compatíveis com as estratégias de ajuste fiscal. Ampliando os esforços na direção de uma política mais agressiva para a gestão de pessoal e, obtendo a cooperação das elites interessadas no ajuste fiscal, a reforma teve ganhos expressivos. 
uma forte aversão ao risco fiscal. Na realidade, conforme demonstrei em trabalho anterior, a proposta de mudança institucional foi percebida como "uma ameaça à estrutura de controle burocrático" nas relações entre a administração direta e indireta no Governo Federal e, ainda, a mudança institucional não foi percebida como um mecanismo capaz de produzir impactos de curto prazo no problema do equilíbrio fiscal. Atores estratégicos com poder de veto na burocracia governamental, tais como a Casa Civil na Presidência, o Ministério da Fazenda, e o Ministério do Planejamento e O rçamento, mais percebiam a reforma administrativa como uma questão mais diretamente associada aos processos de redução de pessoal e de controle de custos com a máquina administrativa, do que em introduzir mudanças substanciais nos arranjos institucionais existentes, mesmo que estes fossem cruciais para a elevação da performance. A elevação da performance fiscal aparece como tarefa crucial dos reformadores, desde 1995.

Apesar de não ter sido implementada a contento, fica claro que, ao lidar com as dimensões fiscais, as reformas não tocam no problema crônico da burocracia brasileira, que é um problema da crise de esgotamento de sua organização, gestão, e modelo de avaliação do desempenho na provisão de políticas públicas. A mudança destas condições depende, em grande medida, de uma grande transformação nos incentivos e, no seu sentido mais amplo, nos padrões de relacionamento entre política e administração.

A importância fundamental desta relação nas condições do caso brasileiro pode ser compreendida a partir de abordagens consagradas no campo das políticas públicas e dos estudos burocráticos que emergiram nos anos 50 e 60 , as quais ilustram os limites da racionalidade administrativa e que tornam a política um elemento decisivo no processo de implementação das mudanças, especialmente em contextos de incerteza, ambiguidadese elevada complexidade, como é o caso das reformas administrativas.

As reformas e seu êxito dependem da capacidade das organizações implementadoras políticas de agir estrategicamente e de formar alianças 
estratégicas diante de processos de disputa de poder no contexto da arena de políticas públicas. Lindblom (1959) é decisivo ao considerar a importância de tais dimensões analíticas no estudo da administração pública que são compreendidos como "muddling through" na formulação original; da capacidade de lidar com as demandas conflitantes oriundas da arena da reforma administrativa, através de processos de mixed-scanning, como sugere Etizioni (1967). Estas categorias analíticas permitem compreender mais efetivamente a noção de que as políticas e sua implementação dependem em grande medida nos contextos e das condições locais de estruturação em torno do conflito do poder, tal qual nos sugerem as formulações originais sugeridas por Guerreiro Ramos (1983). A interação entre política e administração passa a ser decisiva para compreender porque algumas iniciativas de reformas são mais exitosas em termos comparativos.

A mudança institucional foi estruturada a partir da questão do poder e, mais especificamente, em termos da estruturação do controle sobre a autonomia gerencial, orçamento, e os recursoshumanos. A delegação dessas dimensões para as burocracias gerenciais implicou uma possibilidade de perda de controle e de poder sobre as instituições da Administração indireta. A proposta de alterar os mecanismos e a lógica da velha ordem institucional, com uma proposta de "nova divisão de responsabilidades" visando elevação da performance não encontrou resposta cooperativa. $0 \mathrm{~s}$ beneficiários da ordem preferem manter as instituições e cooperar estrategicamente com o ajuste fiscal.

A questão dos controles assume o foco principal da resistência organizada. 0 problema da organização da governança pública em torno da performance não assumiu centralidade na experiência brasileira de 1995. Embora a elevação da performance seja a motivação básica para a reforma, o modo específico pelo qual os diversos atores percebem e calculam os custos e os benefícios gerad os pela mudança da estrutura de organização do controle, é fundamental para explicar o problema da falha no plano da 
implementação. Q uanto mais uma dada política de reforma propõe alterar radicalmente a forma de controle que regula a relação entre implementação e formulação das políticas públicas, maiores as chances para o insucesso das reformas administrativas, sobretudo aquelas em contextos democráticos, de elevada fragmentação e descontrole, bem como marcados por um legado de reduzida performance como ilustra o caso brasileiro.

\section{Considerações Finais}

Reformas gerenciais da Administração Pública sugerem o gradual movimento em direção a uma lógica de organização orientada pela performance. Essa lógica está associada à criação de uma matriz institucional orientada pelos resultados e dotados de modelos de delegação que privilegiem a 'accountability', a participação e a descentralização dos controles burocráticos. A ampliação da esfera pública na provisão de serviços públicos tem sido considerada a base normativa de um novo papel do Estado e um novo modelo de governança pública que possa reorientar as formas tradicionais de envolvimento entre Estado, mercado e sociedade civil na produção e gestão de políticas públicas. O s governos rapidamente passaram a empreender esforços para construir novos modelos de governança na Administração Pública e enfrentaram consideráveis limites para organizar e institucionalizar novos incentivos que alterassem as formas tradicionais de controles burocráticos.

A questão fundamental tratada por este artigo foi a de compreender em que condições são erigidas fortes restrições para a institucionalização destes novos modelos. A análise comparada revela que grande parte da interpretação dos mecanismos causais da falha seqüencial nas reformas administrativas reside na reduzida capacidade de conseguir a cooperação dos atores com poder de veto, em torno dos objetivos programáticos das reformas, especialmente em contextos de forte pressão por ajuste fiscal. A 
tensão que se estrutura entre o ajuste fiscal e a mudança institucional num dado contexto de reformas mostra-se decisiva para que se possa entender as razões para a implementação das mudanças gerenciais.

É em torno do controle (mais amplamente do poder) que se estruturam os entraves para que se possa conseguir a cooperação. 0 conflito de poder é fundamentado na existência de um "dilema do controle" com o qual se deparam os atores que tentam implementar as novas burocracias orientadas pela performance. A expansão da autonomia gerencial, ou mais amplamente das liberdades gerenciais, nem sempre são compatíveis com os ajustes fiscais. Esta contradição é tão mais intensa, quanto mais reduzida é a tolerância estratégica ao risco de desequilíbrio fiscal. Descentralização de políticas públicas e capacidade fiscal dependem de condições específicas para o êxito das reformas gerenciais. Apesar de ser a matriz institucional considerada como decisiva para a transformação dos incentivos burocráticos e sua relação com os resultados, a dimensão do ajuste fiscal emerge como preponderante nas condições contemporâneas de democratização com desequilíbrio fiscal. A análise do caso brasileiro é consistente com a realidade em outros contextose diz muito sobre como os atores reagem às complexas relações entre ajuste gerencial e performance fiscal.

\section{M anagement challenges in the reconfiguration of the Brazilian bureaucratic administration}

\section{Abstract}

The article focuses on the question of the limits for the development of new management bureaucracies within the context of contemporary administrative reforms. The central argument is that the management reforms encounter considerable difficulties in establishing the new performance driven institutional 
models, due to the preponderance of the fiscal adjustment. The construction of the argument is based on two complementary levels of analysis. The first level deals with comparative evidences provided by studies and researches that examined the limits of the implementation of management reforms of public administration in different countries and conditions. The second level focuses on the specific reasons for not implementing the new performance driven bureaucracies in the strategy of management administrative reform pursued by the Brazilian Federal Government in 1995.

Keywords: State reform. Institutional change. Bureaucracy. N ew public management. Public policies. Public governance.

\section{Referências}

BAN GU RA, Yusuf. Public Sector Restructuring: the institutional and social effects of fiscal, managerial and capacity-building reforms. Geneva. U nited Nations. UN Research Institute for Social Development, 2000.

BARZELAY, Michael. Breaking Through Bureaucracy: a new vision for managing in government. Berkeley. University of California Press, 1992.

BO W O RN W ATHANA, B. Transforming bureaucracies for the 21st century: the new democratic governance paradigm, Public Administration Q uarterly, Vol. 21 N o.3, 1997. pp.295-308.

BRESSER PEREIRA, Luiz Carlos, Reflexões sobre a Reforma Gerencial Brasileira. Revista do Serviço Público. n 4. out-dez, 1999.

BRESSER PEREIRA, Luiz Carlos. Reforma do Estado para a Cidadania: a reforma gerencial brasileira na perspectiva internacional. São Paulo: Editora 34, 1998.

BRESSER PEREIRA, Luiz Carlos. Do Estado Patrimonial ao Gerencial. In Sachs, Ignacy, Jorge W ilheim e Paulo Sérgio Pinheiro (orgs). Brasil: um século de transformações. São Paulo: Ed. Companhia das Letras, 2001. pp.222-259.

BRESSER PEREIRA, Luiz Carlos. Democracy and Public Management Reform. Oxford: Oxford University Press, 2004

BRESSER PEREIRA, Luiz Carlos. The Structural Public Governance Model. International Public Management Review, vol 8(1), 2007. pp. 16-32.

CAMERO N, Kim S. Effectiveness as Paradox: consensus and conflict in conceptions of organizational effectiveness. Management Science, vol 32(5), 1986. Pp. 539-553.

DAH L, Robert. Polyarchy: Participation and O pposition. N ew Haven. Yale U niversity Press, 1972. 
DAHL, Robert. Por que mercados livres não bastam? Revista Lua Nova, n.28-29, 1993. ETZIO NI, Amitai. Mixed-Scanning: a "third" approach to decision-making. Public Administration Review, 27, 1967. pp.385-92.

EVANS, Peter. Development as Institutional Change: the pitfalls of monocropping and the potentials of deliberation. Studies in Comparative International Development, vol 38 (4), 2004. pp.30-52.

GUERREIRO RAMOS, Alberto. Administração e Contexto Brasileiro. Rio de Janeiro. Ed. FGV, 1983.

HALL, Peter A. and Rosemary C. Taylor (1996). Political Science and the Three New Institutionalisms. Political Studies, XLIV, 1996. pp.936-957.

HEREDIA, Blanca; SCHNEIDER, Ben Ross (eds). Reinventing Leviathan: the politics of administrative reform in developing countries. Miami, FL: North-South Press at University of Miami, 2003.

GRIN D LE, M erilee S. Challenging the State: crisis and innovation in Latin America and Africa. New York. Cambridge University Press, 1996.

IDB. Latin America After a Decade of Reforms. Economic and Social Progress in Latin America. Washington D.C, 1997.

JANN, Werner; REICHARD, Christopher. M elhores Práticas na Modernização do Estado. Revista do Serviço Público, n.3. Jul-Set, 2002. pp.30-50.

LIN D BLO M, Charles E. The Science of M uddling Through. Public Administration Review, 19 (2), 1959. pp.79-88;

MOORE, Mark. Creating Public Value: strategic management in government. Cambridge. Harvard University Press, 1997.

PUTNAM, Robert. Making Democracy Work. New Jersey. Princeton University Press, 1993.

NORTH, Douglass. Institutions, Institutional Change, and Economic Performance. New York. Cambridge U niversity Press, 1990.

NEE, Victor; O PPER, Sonja. "On Politicized Capitalism". In Nee, Victor and Richard Swedberg (orgs). On Capitalism. Stanford. Stanford U niversity Press, 2007. pp.93-128. NU NES, Edson. A Gramática Política do Brasil. Rio de Janeiro: Jorge Zahar Editores, 1993.

O LIVER, Christine. Strategic Responses to Institutional Processes. Academy of Management Review, vol 16(1), 1991. pp.145-179.

OSTROM, Elinor. Governing the Commons: the evolution of institutions for collective action. Cambridge. Cambridge U niversity Press, 1990. 
PETERS, Guy; LAW RENCE, John Pierre. Governance without government? Rethinking public administration, Journal of Public Administration Research and Theory, vol 8(2), 1998. pp. 223-243.

POLIDANO, Charles; DAVID, Hulme; MINOGUE, Martin. Beyond the New Public Management: changingideas and practices in governance. Edward Elgar Publisher, 1997. PO LID ANO, Charles. The N ew Public Management in Developing Countries. Public Policy and Management. Working Paper n. 13. M imeo, 1999.

PO LIDANO, Charles. Why Civil Service Reforms Fail?. ID PM Public Policy and Management. Working Paper no.16. Mimeo, 2001.

PO LLIT, Christopher; BO U CKAERT, Geert, Avaliando reformas da gestão pública: uma perspectiva internacional. Revista do Serviço Público, n.3. Jul-Set, 2002. pp.05-30.

PRZEW O RSKI, Adam. "Sobre o desenho do Estado: uma perspectiva agent x principal". In: BRESSER PEREIRA, Luiz Carlos e SPINK, Peter (orgs). Reforma do Estado e Administração Pública Gerencial. Rio de Janeiro: Editora da Fundação Getúlio Vargas, 1998. pp 39-75.

REZENDE, Flávio da Cunha. Razões da Crise de Implementação do Estado Gerencial. Revista de Sociologia e Política, n.19.Nov, 2002a. pp. 111-121.

REZENDE, Flávio da Cunha. O dilema do controle e a falha seqüencial nas reformas gerenciais. Revista do Serviço Público, n.3. Jul-Set, 2002. pp. 51-76.

REZEN DE, Flávio da Cunha. Por que falham as reformas administrativas? Rio de Janeiro: Editora da Fundação Getúlio Vargas, 2004.

RHODES, R.A.W. Understanding Governance: policy networks, governance, reflexivity and accountability. Philadelphia. O pen University Press, 1997.

RODRIK, Dani; SUBRAMANIAN, Arvind. The Primacy of Institutions (and what this does and does not mean). Finance and Development, June, 2003. pp.31-34.

SHAPIRO, Ian. The State of Democratic Theory. N ew Jersey. Princeton U niversity Press, 2005.

SCH W ARTZM AN, Simon. Desempenho e Controle na Reforma Administrativa. ENAP. Texto para Discussão, 8. Brasília. O utubro, 2001.

SEIDMAN, Harold. Politics, Position, and Power: the dynamics of federal organization. N ew York: Oxford University Press, 1998.

World Bank. World Development Report. The State in a Changing World. Washington D.C, 1997. 